\title{
Adornos corporales y género en las fotografías etnográficas de Yámana/Yagán
}

\author{
Body ornaments and gender in the ethnographic \\ photographs of Yámana/Yagán
}

\author{
Ana Butto ${ }^{1}$ \\ anabutto@gmail.com \\ Danae Fiore ${ }^{2}$ \\ danae_fiore@yahoo.es
}

\begin{abstract}
Resumen
Este trabajo se propone discutir el aporte del estudio de las fotografías etnográficas acerca de los adornos corporales y las regulaciones de género de la sociedad Yámana/Yagán de Tierra del Fuego (Argentina y Chile). Se entiende a la fotografía como un artefacto cultural que permite rescatar múltiples agencias, considerando que los elementos incluidos en la imagen -como los adornos corporales-refieren no sólo a los intereses del fotógrafo sino también a los de los fotografiados. A fin de analizar esos elementos, se estudiaron 428 fotografías etnográficas de Yámanas/Yaganes, obtenidas entre fines del siglo XIX y comienzos del XX; se seleccionaron 140 individuos fotografiados que portaban un total de 171 adornos corporales entre collares, brazaletes y/o tobilleras. Se analizó el vínculo entre tipo de adorno y género de su portador, y se encontró que los collares fueron usados tanto por mujeres como por varones, mientras que brazaletes y tobilleras lo fueron por mujeres. Estos resultados permiten discutir el rol de los adornos en la construcción y regulación de roles de género en la sociedad Yámana/Yagán. Simultáneamente se evalúa el aporte de las fotografías etnográficas como artefactos de cultura material que, mediante la combinación de una mirada antropológica y arqueológica, resultan relevantes para producir nuevos conocimientos sobre el pasado indígena.
\end{abstract}

\section{Palabras clave}

Fotografía, indígena, Yámana, adorno corporal, género, artefacto.

1 Dra. en Arqueología, Consejo Nacional de Investigaciones Científicas (CONICET), Asociación de Investigaciones Antropológicas (AIA) y Universidad Nacional de La Matanza (UNLaM), Argentina. Orcid: 0000-0001-7455-909.

2 Dra. en Arqueología, Consejo Nacional de Investigaciones Científicas (CONICET), Asociación de Investigaciones Antropológicas (AIA) y Universidad de Buenos Aires (UBA), Argentina. Orcid: 0000-0003-1672-3070. 
Forma sugerida de citar: (2017). Butto, Ana, \& Fiore, Danae (2017). Adornos corporales y género en las fotografías etnográficas de Yámana/Yagán. Universitas, XV(27) pp. 67-92.

\begin{abstract}
This work aims to discuss the contribution of the study of ethnographic photographs about the body adornments and the gender regulations of the Yámana/Yagán society of Tierra del Fuego (Argentina and Chile). Photography is understood as a cultural artifact that allows the rescue of multiple agencies, considering that the elements included in the image -such as body ornaments-refer not only to the interests of the photographer but also to those of the photographed. In order to analyze these elements, 428 ethnographic photographs of Yamanas/Yaganes, obtained between the end of the 19th century and the beginning of the 20th century, were studied; of which 140 individuals were photographed carrying a total of 171 body ornaments between necklaces, bracelets and/or anklets. The link between type of ornament and gender of its wearer was analyzed, and it was found that necklaces were worn by both women and men, while bracelets and anklets were worn by women. These results allow us to discuss the role of body ornaments in the construction and regulation of gender roles in Yámana/Yagán society. Simultaneously, the contribution of ethnographic photographs as artifacts of material culture is evaluated, which, by combining an anthropological and archaeological perspective, are relevant to produce new knowledge about the indigenous past.
\end{abstract}

Keywords

Photography, indigenous people, Yámana, body ornament, gender, artifact.

\title{
Introducción
}

Este trabajo se propone discutir cómo la antropología audiovisual y, específicamente, el estudio de las fotografías etnográficas permite comprender el rol que cumplen los adornos corporales usados por los pueblos indígenas en la construcción y regulación de roles de género (Claassen, 1992; Conkey y Gero, 1991; Butler, 2004). El caso que analizaremos es el de la sociedad Yámana/Yagán, cuyo territorio ancestral ${ }^{3}$ abarca el sur del archipiélago de Tierra

3 Existen documentos que demuestran que el nombre yagán fue adoptado por esta sociedad a fines del 
del Fuego (Argentina y Chile), concentrándonos en la forma en que mujeres y varones vistieron los adornos corporales -collares, brazaletes y tobilleras-.

Entendemos que las fotografías etnográficas son índices de una realidad tanto representada como reproducida mediante la captura de la luz y de los referentes ubicados frente al dispositivo fotográfico, por lo que no sólo reflejan la visión del productor de la imagen, sino que el referente real también aporta a su representación (Fiore y Varela, 2009). De esta manera, consideramos que es posible rescatar información acerca de los indígenas fotografiados y, en este caso, acerca del uso de sus adornos corporales. En este trabajo retomamos el concepto de género como una construcción del cuerpo sociocultural e históricamente situada, que implica características físicas y comportamentales que incluyen y exceden al sexo, orientando el desarrollo de elementos como apariencia física, postura, movimiento/gesticulación, tonos del habla, modos de vestimenta y ornamentación, generando un rol social individual pero emergente de la interacción con otros individuos (Conkey y Spector, 1984; Claassen, 1992; Sørensen, 2000). Por lo tanto, entendemos que los adornos corporales indígenas participaron en dicha construcción de géneros en las sociedades indígenas fueguinas (Fiore, 2007).

Por ello, centramos nuestro estudio en un total de 428 fotografías etnográficas de la sociedad Yámana/Yagán, obtenidas entre fines del siglo XIX y comienzos del XX, prestando especial atención a los individuos que portaban adornos corporales. De esa muestra, se seleccionaron 86 fotografías que retrataron a 140 individuos, que usan un total de 171 adornos corporales -124 collares, 20 brazaletes y 27 tobilleras-, los cuales fueron analizados especialmente a partir del género de su portador. A partir de esas variables de análisis, esperamos discutir el rol de los adornos en las construcciones y regulaciones de género de la sociedad Yámana/Yagán, así como el aporte de las fotografías etnográficas y la antropología audiovisual a la hora de conocer esas regulaciones de género (sensu Butler, 2004).

\section{Caso de estudio y estado de la cuestión}

Los Yámana/Yagán son un pueblo originario cuyo modo de vida tradicional fue cazador-recolector-pescador con movilidad canoera, que ocupó la

siglo XIX, pero no se cuenta con información para tiempos anteriores (Piana en Fiore y Varela, 2009). 
porción sur de la Isla Grande de Tierra del Fuego y las islas del archipiélago fueguino hasta el Cabo de Hornos (Orquera y Piana, 2015). Los ancestros de los Yámana/Yagán habitaron dicho territorio desde los 7300 años AP cal -antes del presente ${ }^{4}$ - (Orquera y Piana, 1999). Su subsistencia se basaba en la caza de lobos marinos, guanacos y aves, la pesca de peces y la recolección de moluscos, además del aprovechamiento ocasional de ballenas varadas (Gusinde, 1986 [1937]; Orquera y Piana, 1999). Para el aprovechamiento de estos recursos desarrollaron una tecnología de movilidad y captura de presas específica: las canoas, los arpones y otras armas arrojadizas que facilitaban los traslados y el transporte, así como la captación de recursos imprescindibles (Orquera y Piana, 2015). Los campamentos, constituidos por chozas de troncos, ramas y hojas, eran habitados por grupos familiares. Ocasionalmente se daban reuniones de grandes grupos, por el varamiento de una ballena o para celebrar los ritos de iniciación a la adultez mixtos -chiéjausy masculinos -kina- (Gusinde, 1986 [1937]). Los viajeros que entraron en contacto con este grupo étnico desde el siglo XVII señalaron la ausencia de jefes o de figuras con una autoridad real (Fitz Roy, 1839). La división sexual del trabajo era semi-igualitaria, ya que la distribución de las tareas femeninas y masculinas era complementaria (Gusinde, 1986 [1937]; Fiore, 2007).

Muchos de los viajeros que entraron en contacto con los Yámana/Yagán señalaron el uso de adornos corporales (Fitz Roy, 1839; Hyades y Deniker, 2007 [1891]; Bridges, 2005 [1948]; Gusinde, 1986 [1937]). La pintura facial y corporal ${ }^{5}$ es mencionada por la mayoría de los viajeros, así como el uso de collares, brazaletes y tobilleras por parte de todos los grupos de edad (Martial, 2007 [1888]). Las diademas de plumas ${ }^{6}$, utilizadas en las ceremonias, fueron observadas por menos viajeros (Gusinde, 1986 [1937]). Junto con los viajeros, que a partir del siglo XVII comenzaron las exploraciones del territorio fueguino, llegaron nuevos artefactos y materias primas, entre ellos, collares y brazaletes de cuentas europeas que fueron adoptados por los Yámana/Yagán (Orquera y Piana, 2015).

4 En arqueología, los fechados radiocarbónicos se presentan como años AP “antes del presente”, contabilizando la fecha desde 1950 hacia el pasado.

5 La pintura facial retratada en las fotografías etnográficas de Yámana/Yagán ha sido ampliamente estudiada por Fiore (2002) y no será abordada en este trabajo.

6 Las diademas de plumas usadas en las distintas ceremonias serán el foco de otro trabajo, y no serán abordadas en este artículo. 


\section{Figura 1}

\section{Mapa de Patagonia y Tierra del Fuego y ubicación del territorio ancestral de los Yámana/Yagán}

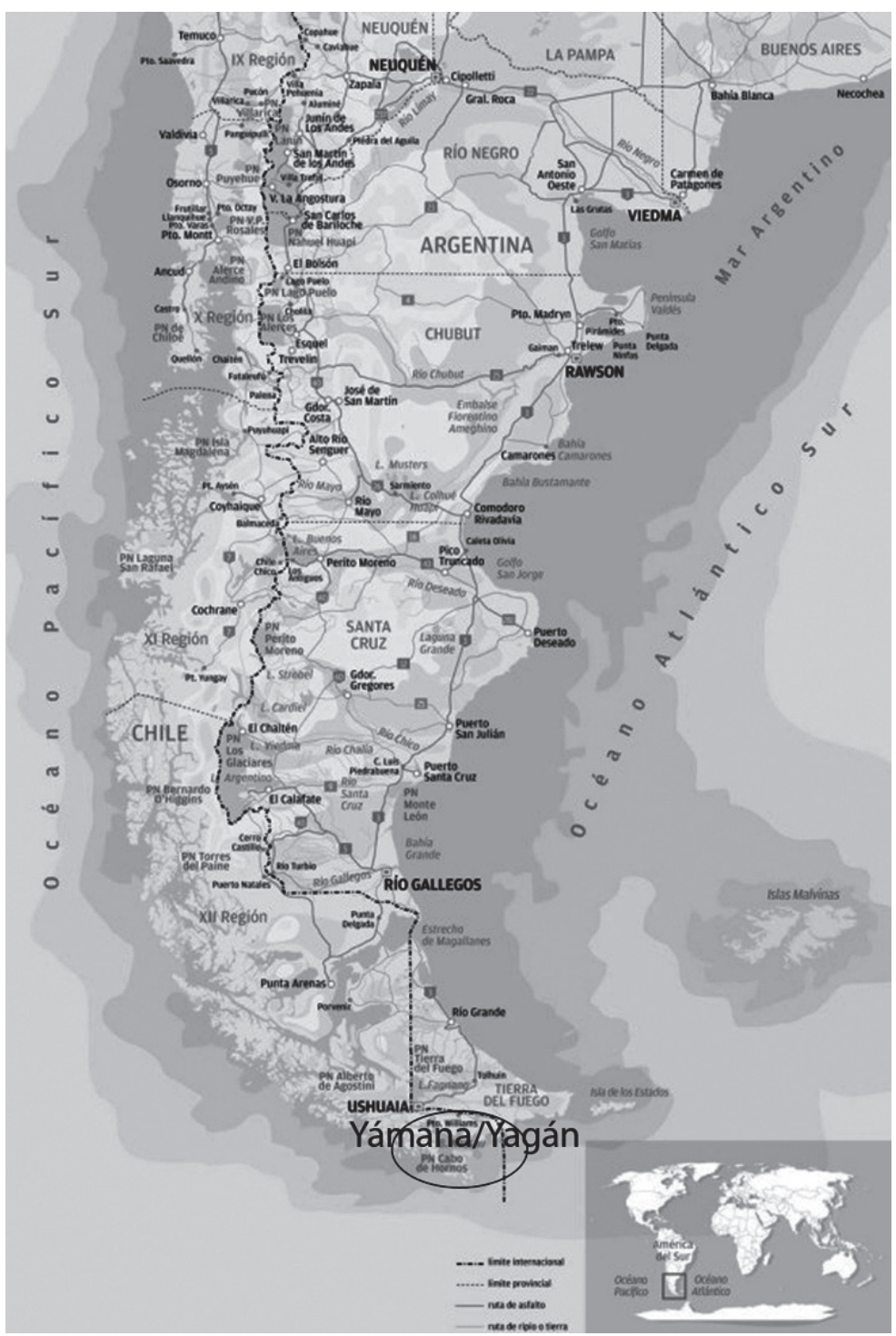

Fuente del mapa: www.patagoniatravelfinder.com 
Debido a la atracción que ejerció este pueblo originario fueguino, por ser considerado una "supervivencia" de un modo de vida pasado que se extinguía o como especímenes exóticos contemporáneos (Gusinde, 1986 [1937]; Penhos, 2005), existe un amplio corpus de fotografías de los Yámana/Yagán. Éstas han sido estudiadas por investigadores de múltiples disciplinas, centrados usualmente en tres elementos: la representación, la circulación y el referente representado.

Los estudios centrados en la representación enfatizaron en la forma en que los fotógrafos produjeron imágenes que se condicen más con su imaginario de lo salvaje que con la realidad de las poblaciones indígenas, para lo cual manipularon recursos y dispositivos (Alvarado, 2007; Edwards, 1992). Entre esas múltiples manipulaciones resalta la imposición de la desnudez, que se vuelve patente en cinco retratos tomados a una mujer Yámana/Yagán por los fotógrafos de la Misión Científica Francesa al Cabo de Hornos -instalada en la región entre 1882 y 1883-, en la que las poses de la joven dejan entrever la clara intención erótica de los fotógrafos (Carreño, 2002). Por otro lado, las manipulaciones de la vestimenta pueden ser clasificadas en tres tipos: la "vestidura" que resalta la vestimenta autóctona fueguina, para lograr una correspondencia exacta entre sujeto indígena, indumentaria tradicional y escenario natural; la "investidura" que implicaba la imposición de indumentaria occidental, para presentar a los fueguinos como seres pulcros y ordenados, capaces de ser incorporados a la civilización; y el "despojo" de algunos indígenas vestidos con restos de indumentarias occidentales, mostrándolos como seres desposeídos (Alvarado y Mason, 2005). Otro tipo de manipulación es la que recrea ambientes naturales, escondiendo el cautiverio de grupos fueguinos exhibidos en ferias internacionales y zoológicos humanos, a fin de "crear la ilusión de un ambiente «natural〉" (Báez y Mason, 2006, p. 56) acorde al imaginario acerca de las poblaciones indígenas.

Otros enfoques subrayan la circulación social e institucional de estas imágenes de indígenas fueguinos y enfatizan en su difusión como parte de manuales escolares. Las imágenes de indígenas fueguinos incluidas en los manuales escolares chilenos acentúan su desnudez, precariedad y primitivismo, a la vez que construyen una identidad fueguina arbitraria, al realizar adscripciones étnicas erróneas (Báez, 2005). Del lado argentino, las imágenes de fueguinos publicadas en los manuales escolares obedecen a dos tendencias: una que muestra una imagen prístina de los pueblos indígenas vistiendo y manipulando sólo elementos autóctonos y otra que los muestra 
como seres incorporados al Estado-nación, manipulando elementos occidentales (Saletta, 2011). En ambos casos, la fotografía es utilizada como si se tratara de una representación fidedigna del pasado, pero no como documento de los procesos de transculturación vividos por estos grupos desde fines del siglo XIX.

La concepción de la fotografía como un artefacto de cultura material socialmente construido, que aporta información sobre el fotógrafo y el fotografiado, permitió recuperar y analizar información acerca de los referentes representados (Edwards, 1992; Fiore y Varela, 2009). Esta postura entiende que no todos los elementos de una imagen responden a imaginarios y estrategias desplegadas por los fotógrafos, sino que la fotografía permite la inclusión de la materialidad cotidiana que escapa a la mirada del colonizador y que, por representar lo rutinario (Giddens, 1995), informa acerca de las prácticas culturales propias de estos pueblos (Fiore, 2005; Fiore y Varela, 2009; Butto, 2016). En esta línea de investigación se han estudiado comparativamente las fotografías de pinturas corporales de Yámana/Yagán y Shelk'nam, que evidenciaron distintos usos de la pintura corporal como elementos que producen identidades y divisiones sociales, como formas de ejercer el poder y de construir roles de género (Fiore 2005, 2007). A su vez, al estudiar la cultura material manipulada en las fotografías por las tres sociedades fueguinas -Shelk’nam, Yámana/Yagán y Alakaluf/Kawésqar- se encontró que cada sociedad produjo y manipuló distintos tipos de artefactos y que la adopción de cultura material foránea fue distinta en cada caso, porque los procesos de contacto con la sociedad occidental difirieron de acuerdo a los agentes occidentales enfrentados (militares, misioneros religiosos, etc.) y a los valores y prácticas de cada sociedad indígena (Fiore, 2007; Fiore y Varela, 2009; Butto, 2016). Estos estudios de los sujetos representados en las fotografías etnográficas de Yámana/Yagán demuestran que es posible identificar y evaluar las pautas de manipulación de cultura material y el género de los propios sujetos fotografiados. En el caso que nos ocupa, nos concentraremos en el vínculo entre ornamentos corporales y roles de género.

\section{Conceptos y métodos: fotos, género y ornamentos}

La fotografía fue entendida, en sus comienzos, como una analogía directa de la realidad, ya que su obtención mecánica implicaba un carácter supues- 
tamente objetivo (Bazin, 1960). El foco en el modo mecánico de producción de la imagen fotográfica permitía pensarla como una impresión, porque su procedimiento era el de la transferencia (Costa, 1991). De esta manera, la fotografía fue considerada como transparente y como un "mensaje sin código" (Barthes, 2004), que proveía "el testimonio visual y material de los hechos a los espectadores ausentes de la escena" (Kossoy, 2001, p. 30). Esta capacidad de registro objetivo convirtió a la fotografía en una gran herramienta de documentación para los primeros etnógrafos -junto con la escritura y la grabación de sonido-, ya que permitía perpetuar evidencias de su trabajo de campo (Collier, 1995; Grimshaw, 2001). Así, la fotografía permitía obtener una memoria detallada y genuina de esos "otros" estudiados y los acontecimientos vividos durante el trabajo de campo, ayudando a la consolidación de la antropología como una disciplina profesional (Naranjo, 2006).

Pero para los teóricos posmodernos la objetividad de las imágenes técnicas fue una ilusión, ya que la fotografía es siempre simbólica (Flusser, 1990). La fotografía adquiriría distintos significados según las circunstancias sociales y culturales, revelando la relatividad, ambigüedad y mutabilidad de su identidad. Así, su significado dependería de una práctica discursiva sumergida en relaciones de poder-saber, cuyas interpretaciones dependen de los usos y funciones de ciertas instituciones que han definido el estatus de la fotografía (Bourdieu, 1979; Tagg, 2005). A partir de esta idea de que el dispositivo fotográfico es siempre un dispositivo culturalmente codificado (Sekula en Batchen, 2004), la antropología comenzó a repensar el papel que jugó la fotografía dentro de las políticas de representación de la alteridad, enfatizando en las construcciones visuales del colonialismo (Scherer, 1995). Así, la antropología visual centró su análisis en las fotografías históricas como productos culturales coloniales que crearon y reprodujeron arquetipos populares de "lo exótico" entendido como lo culturalmente diferente (Naranjo, 2006).

Desde una postura "crítica", algunos teóricos han retomado la concepción de la fotografía como índice de la realidad representada, pero simultáneamente construida por los sesgos de sus productores. Estos autores destacan la conexión física entre el referente representado y la imagen fotográfica, entre el objeto y el signo visual que emana de aquél (Peirce, 1995). La singularidad del índice fotográfico se debe a que, si esa imagen es la huella lumínica de un objeto real que ha estado allí, entonces se trata de una marca única e irrepetible de ese sujeto/objeto. Así, aunque las imágenes fotográficas puedan reproducirse técnicamente (Benjamin, 2015) y puedan manipularse me- 
diante numerosos procesos de edición (Kossoy, 2001), el negativo que captó originalmente al referente es tan único como el propio referente. De esta manera, la fotografía remite a la existencia de ese referente real, convirtiéndose en evidencia, en testimonio de esa realidad representada (Freund, 2015). Esta idea de índice es la base para comprender la situación referencial de la fotografía, ya que la copresencia entre fotógrafo, cámara y fotografiado sólo se da durante el acto fotográfico, pero evidencia dicho contacto por un lapso mayor: el tiempo de vida de la fotografía como artefacto de cultura material (Dubois, 2008; Fiore y Varela, 2009). La concepción de las fotografías como "artefactos socialmente construidos que nos cuentan algo sobre la cultura reflejada así como la cultura del que toma dichas imágenes" (Ruby, 1996, p. 1346) permite desarrollar una arqueología visual que rescate tanto la agencia del fotógrafo como la del fotografiado (Fiore y Varela, 2009). Entendemos que en el "instante infinito" (Dubois, 2008) en que fotógrafo y referente se encuentran para realizar la toma fotográfica se da un "encuentro de subjetividades" (Fiore, 2005) que está sujeto a los diferentes grados de libertad de cada uno de los individuos: fotógrafo y fotografiado. Es innegable que los fotógrafos tienen mayor libertad de acción y poder de decisión sobre la imagen, ya que controlan más estadios de su producción: manejan el dispositivo fotográfico, su revelado y positivado y eventualmente su circulación -aunque ésta puede escapar a su control- (Poole, 2002).

Sin embargo, es también innegable que la presencia y agencia del sujeto fotografiado son imprescindibles para que ocurra la captura fotográfica; en otras palabras, sin referente real no hay fotografía. Así, aunque el grado de libertad sea siempre mayor en los grupos que detentan el poder, es decir, en los fotógrafos, esta distinción no anula el margen de injerencia de los sujetos fotografiados respecto de su propia representación. Consideramos entonces que en la producción de toda imagen fotográfica operan tanto el productor como el referente representado, con diferentes grados de pregnancia en la imagen fotográfica y es en esa relación diálógica en la que se construye la imagen (Butto, 2016). Por lo tanto, es posible captar tanto la visión del fotógrafo como la agencia del sujeto fotografiado, desde una perspectiva teórica en la cual ambos son individuos activos durante la toma fotográfica y pueden grabar su propia impronta e intereses en pugna. De esta manera, a pesar de los sesgos del fotógrafo, del editor, del curador y del archivador, la agencia del sujeto fotografiado está allí, esperando ser descubierta. Así, entendemos que la antropología audiovisual puede encontrar en la arqueología 
visual (sensu Fiore y Varela, 2009) un aliado que permite rescatar el valor de las fotografías etnográficas, que documentan el pasado reciente de las poblaciones indígenas.

Para desarrollar una arqueología visual de los ornamentos corporales de la sociedad Yámana/Yagán, seleccionamos una muestra total de 428 fotografías etnográficas obtenidas entre 1882 y 1971 por un mínimo de 25 fotógrafos conocidos -además de otros anónimos-. La conformación de esta muestra implicó la búsqueda, identificación y selección de fotografías de indígenas yámana/yagán en diversos archivos y publicaciones. La adscripción étnica de los sujetos fotografiados se realizó sobre la base de varios criterios complementarios: a) la adscripción por parte del archivo, b) los epígrafes de los fotógrafos, c) la cultura material manipulada por los sujetos fotografiados, d) el paisaje y e) el aspecto físico de los indígenas fotografiados.

Estas fotografías fueron analizadas en otros trabajos de acuerdo a la información visible en tres niveles (Fiore y Varela, 2009; Butto, 2016):

a. el nivel de la fotografía, evaluando los procesos de formación del registro fotográfico: fotógrafo/a, propósitos, lugares visitados, tiempo de estadía, vínculos con las personas fotografiadas, tipos de toma, adscripción étnica de las personas fotografiadas y contexto fotografiado;

b. el nivel de los individuos fotografiados: género, edad, rol social y nombre de cada persona;

c. el nivel de los artefactos fotografiados: tipos de choza, vestimenta, ornamentos, objetos.

Para este trabajo seleccionamos 86 fotografías, en que se retratan 140 individuos que usan adornos corporales como collares, brazaletes y tobilleras. Esos individuos retratados fueron analizados de acuerdo a su género y al tipo de ornamento/s usado/s, a fin de discutir si existían ornamentos exclusivamente femeninos, exclusivamente masculinos o compartidos por ambos géneros. Debido a que el proceso social de construcción del género se despliega mediante prácticas de uso de ornamentos corporales (Conkey y Spector, 1984; Conkey y Gero, 1991; Fiore, 2007), que construyen el rol de género del sujeto portador tanto en su auto-percepción como en la percepción por otros, el análisis del vínculo entre personas y ornamentos resulta especialmente relevante para conocer estas prácticas. Asimismo, el hallazgo de tendencias recurrentes sugiere la existencia de regulaciones de géne- 
ro (sensu Butler, 2004) que habrían funcionado en esta sociedad indígena. Cabe acotar que el análisis propuesto opera mediante una clasificación dicotómica de géneros: masculino y femenino, sin que ello implique que dicha dicotomía operase taxativamente en la sociedad Yámana/Yagán. Sin embargo, dado que existen indicios muy sutiles de variedades intra-género o categorizaciones de género por fuera de dicha dicotomía, ella resulta relevante para plantear un panorama inicial sobre este tema (Fiore, 2007).

\section{Adornos corporales en mujeres y varones Yámana/Yagán}

El primer análisis a realizar a esta muestra de 428 fotografías etnográficas de Yámanas/Yaganes es la cantidad de individuos fotografiada. Dado que la fotografía registra los individuos que posaron frente al dispositivo fotográfico, es posible registrar una "población fotografiada" y a partir de ella construir una "demografía fotográfica" (Fiore y Varela, 2009). Esta estructura demográfica fotografiada diferirá de la demografía real, en tanto que una misma persona puede ser contabilizada varias veces (todas las que fue fotografiada). Lamentablemente, no existen datos suficientes que permitan construir una demografía real, ya que en los primeros tres Censos Nacionales solo se contabilizó la cantidad aproximada de indígenas que habitaban los Territorios Nacionales ${ }^{7}$. Así, aunque no pueda ser comparada con una demografía real, esta demografía fotográfica aporta un interesante panorama sobre "la composición poblacional de los grupos fotografiados, y por extensión, de la población nativa contactada por los occidentales" (Fiore y Varela, 2009, p. 199).

De los 1574 individuos Yámana/Yagán retratados, más de la mitad eran varones $(52 \%, \mathrm{~N}=820)$, menos de la mitad eran mujeres $(45 \%, \mathrm{~N}=711)$ y algunos individuos no pudieron ser identificados en cuanto al género $(\mathrm{N}=43)$. En esta muestra encontramos un total de 171 ornamentos corporales usados por 140 individuos: 124 collares, 20 brazaletes y 27 tobilleras.

Los collares usados por los Yámana/Yagán fueron mencionados por la mayoría de los viajeros que entraron en contacto con ellos (Fitz Roy, 1839;

7 Pero existen otros datos confiables: Thomas Bridges estimó 2 500, 3000 personas yámana/yagán para tiempos anteriores a 1880, de las que en 1884 sobrevivían poco más de 1000 . Para el momento que Gusinde visitó Tierra del Fuego (1920) los Yámana/Yagán eran 73, 74. Ver más datos en Orquera y Piana, 2015. 
Hyades y Deniker, 2007 [1887]; Bridges, 2005 [1948]; Gusinde, 1986 [1937]). Los collares pueden ser caracterizados y clasificados de acuerdo a su morfología y materia prima, las cuales permiten deducir su carácter autóctono o foráneo. Los collares autóctonos usados por los Yámana/Yagán eran de tres tipos: 1) de valva de caracol agujereadas enhebradas en cuerdas $\left.^{8}, 2\right)$ de huesos de ave también enhebrados en cuerdas y 3 ) de cuero o tripa trenzada (Fitz Roy, 1839; Hyades y Deniker, 1887; Gusinde, 1937 y otros autores citados en Orquera y Piana, 2015, pp. 320-325). A partir de la llegada de exploradores, científicos y misioneros al territorio fueguino los Yámana/Yagán adoptaron elementos occidentales en sus collares, tales como: cuentas de vidrio, botones, fragmentos de vidrio, cerámica o hierro (Orquera y Piana, 2015, p. 325). En las fotografías analizadas solo aparecen algunos tipos de collares (Tabla 1): entre los autóctonos aparecen los collares de hueso (Figura 2), de caracoles (Figura 3) y de cuero, mientras entre los foráneos aparecen los collares de cuentas $^{9}$ de distintos colores -blancas, oscuras y una mezcla de ambas- (Figura 4) y cuentas de metal. Encontramos que la mayoría de los collares fotografiados son foráneos (94\%), mientras la minoría (6\%) son autóctonos.

\section{Tabla 1}

\section{Tipos de collares por género}

\begin{tabular}{|l|c|c|c|c|c|c|c|c|}
\hline \multirow{2}{*}{$\begin{array}{c}\text { Tipo de } \\
\text { collares/ } \\
\text { Género }\end{array}$} & \multicolumn{3}{|c|}{ Autóctonos } & \multicolumn{4}{c|}{ Foráneos } & Total \\
\cline { 2 - 8 } & hueso & caracoles & cuero & $\begin{array}{c}\text { cuentas } \\
\text { blancas }\end{array}$ & $\begin{array}{c}\text { cuentas } \\
\text { oscuras }\end{array}$ & $\begin{array}{c}\text { cuentas } \\
\text { blancas } \\
\text { y oscuras }\end{array}$ & $\begin{array}{c}\text { cuentas } \\
\text { de metal }\end{array}$ & \\
\hline Mujeres & 1 & 2 & - & 17 & 20 & 41 & 1 & 82 \\
\hline Varones & - & - & 4 & 8 & 16 & 14 & - & 42 \\
\hline Total & 1 & 2 & 4 & 25 & 36 & 55 & 1 & 124 \\
\hline
\end{tabular}

Elaboración: Autoras

8 Las cuerdas eran confeccionadas a partir de tendones de ballena, tripa trenzada, fibras retorcidas o cuero (Orquera y Piana, 2015, p. 323).

9 Posiblemente se trate de cuentas de vidrio, pero no es posible verificarlo a partir de las fotografías consultadas. 


\section{Figura 2}

Mujer yámana/yagán, llamada Peine, con pintura corporal ceremonial y vistiendo un collar de huesos

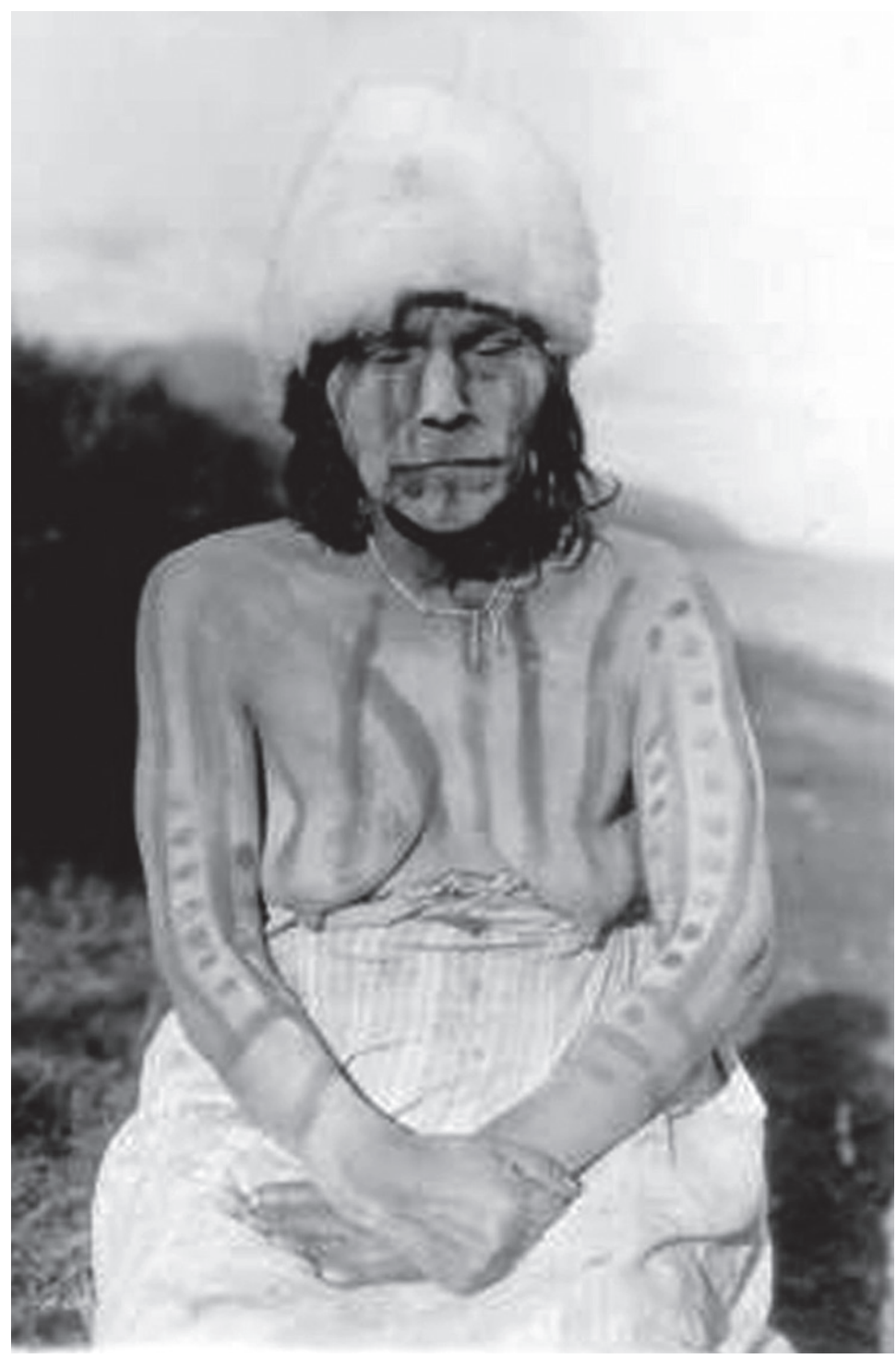

Fotografía de Wilhelm Koppers, 1922. 


\section{Figura 3}

Mujer yámana/yagán vistiendo un collar de caracoles

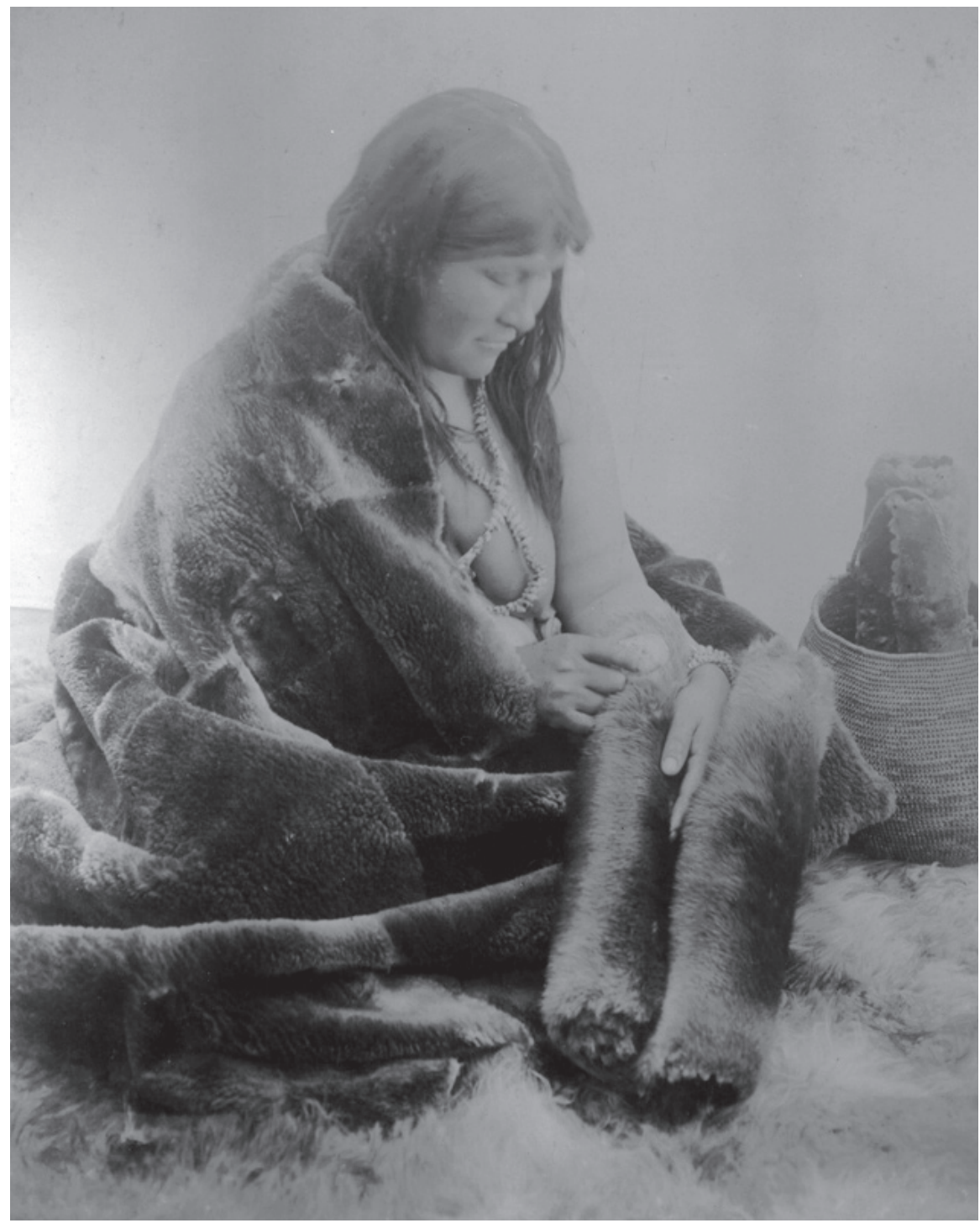

Fotografía de Ángeles Sánchez de Caballero, 1910-1920. 
Figura 4

Jóvenes yámana/yagán vistiendo collares de cuentas foráneas

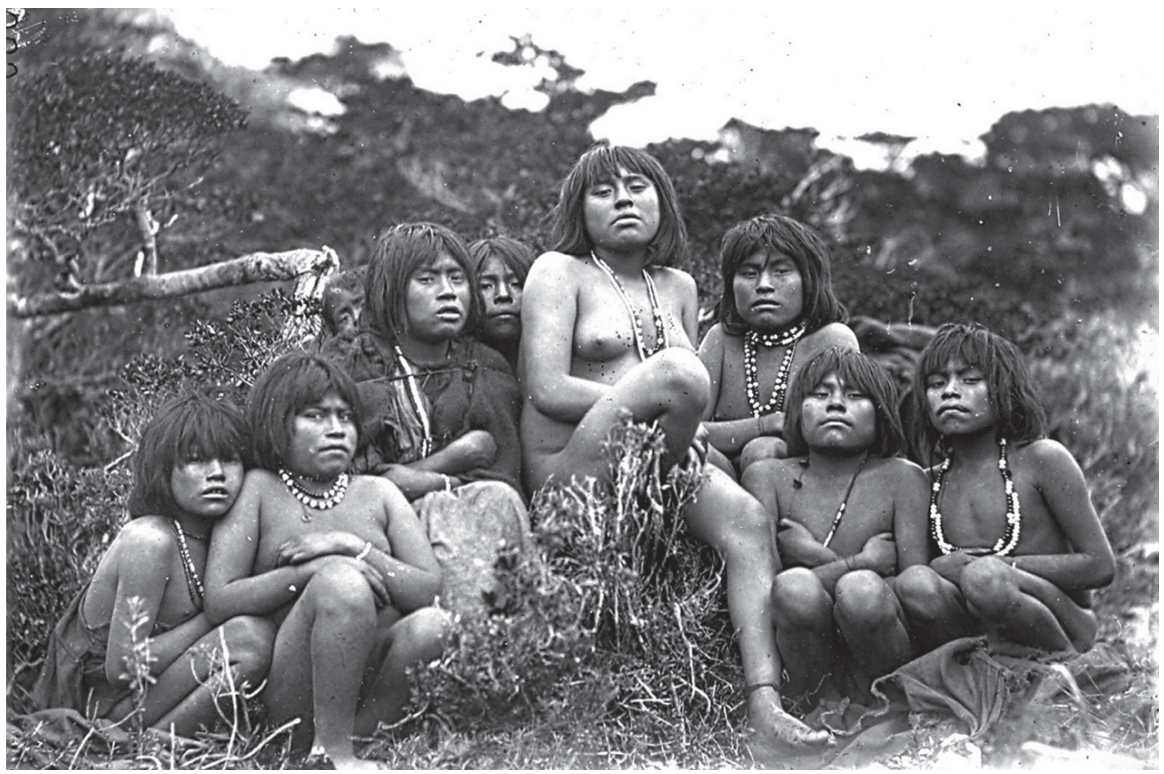

Fotografía de Jean Louis Doze y Edmond Payen, Misión Científica al Cabo de Hornos, 1882-1883.

Respecto del género, encontramos que todos los tipos de collares -salvo los de cuero- eran más usados por mujeres (66\% de 124 collares), siendo al parecer de uso exclusivamente femenino los de hueso, los de caracol y los de cuentas de metal (registrados todos en bajas frecuencias). Varios tipos de collares eran también usados por varones (34\% de 124 collares), siendo exclusivamente masculinos los de cuero. Es decir, las mujeres usaban 6 tipos de collares, de los cuales 3 habrían sido exclusivamente femeninos, mientras que los varones usaban 4 tipos de collares, de los cuales 1 habría sido exclusivamente masculino. Este predominio en cantidad y variedad de collares usados por las mujeres se condice con las observaciones de algunos viajeros y científicos, que habrían señalado la predilección femenina por este tipo de adornos (Fitz Roy, 1839; Hyades y Deniker, 2007 [1887]).

Interesantemente, encontramos que los collares autóctonos aparecen usados en la misma proporción por los varones (50\% de 8 collares autóctonos) 
que por las mujeres (50\%). Estos collares muestran una gran diferencia de género, ya que el único collar de hueso y los dos collares de caracoles eran usados solo por mujeres, mientras los cuatro collares de cuero lo eran solo por varones. Cabe mencionar que los collares de cuero usados por los varones podrían en realidad ser hondas usadas para cazar aves, que solían ser llevadas en el cuello (Orquera y Piana, 2015). De hecho, algunas fotografías retratan varones Yámana/Yagán portando collares de cuero apretados al cuello y hondas -con una tira triangular de cuero y dos correas que llegaban a la altura del ombligo-. Los collares foráneos siguen un patrón diferente, ya que la mayoría eran usados por mujeres (68\% de 117 collares foráneos), y pocos lo eran por varones (32\%). Así, las mujeres usaban más collares de cuentas blancas (68\% de 25 ), de cuentas oscuras (55\% de 36), de cuentas blancas y oscuras ( $75 \%$ de 55), y también el único collar de cuentas de metal.

Encontramos una posible regulación de género respecto del uso de los collares entre los Yámana/Yagán. Los collares autóctonos parecen obedecer a una regulación más estricta de género: las mujeres habrían usado collares de hueso y caracoles y los varones de cuero. Contrariamente, los collares foráneos fueron usados indistintamente tanto por mujeres como por varones, aunque en mayor proporción por las primeras. Este patrón de comportamiento observado en las fotografías etnográficas se condice con el observado por numerosos viajeros que entraron en contacto con los Yámana/Yagán: que los collares eran usados por ambos géneros, pero preferidos por las mujeres (Fitz Roy, 1839; Hyades y Deniker, 2007 [1891]; Gusinde, 1986 [1937]).

Los brazaletes fueron observados y mencionados por algunos de los viajeros que mantuvieron contacto con los Yámana/Yagán (Fitz Roy, 1839; Martial, 2007 [1888]; Hyades y Deniker, 2007 [1891]; Gusinde, 1986 [1937]) y también pueden ser caracterizados y clasificados sobre la base de su morfología y materia prima como autóctonos o foráneos. Los brazaletes autóctonos tenían unos $2 \mathrm{~cm}$ de ancho y eran confeccionados con "aros de cuero de lobo marino" (Martial, 2007 [1888], p. 31) o de guanaco, sujetados mediante una perforación o mediante nudos hechos con lazos de tendón (ver enumeración de citas en Orquera y Piana, 2015). Los brazaletes foráneos estaban compuestos por los mismos elementos occidentales que los collares: cuentas de vidrio y/o cerámica (Orquera y Piana, 2015) (Figura 5). En las fotografías aquí analizadas predominan levemente los brazaletes foráneos (55\% de 20 brazaletes) por sobre los autóctonos (45\%) (Tabla 2). 


\section{Figura 5}

Familia yámana/yagán. Algunos visten brazaletes de cuero, otros brazaletes de cuentas, además de collares y tobilleras

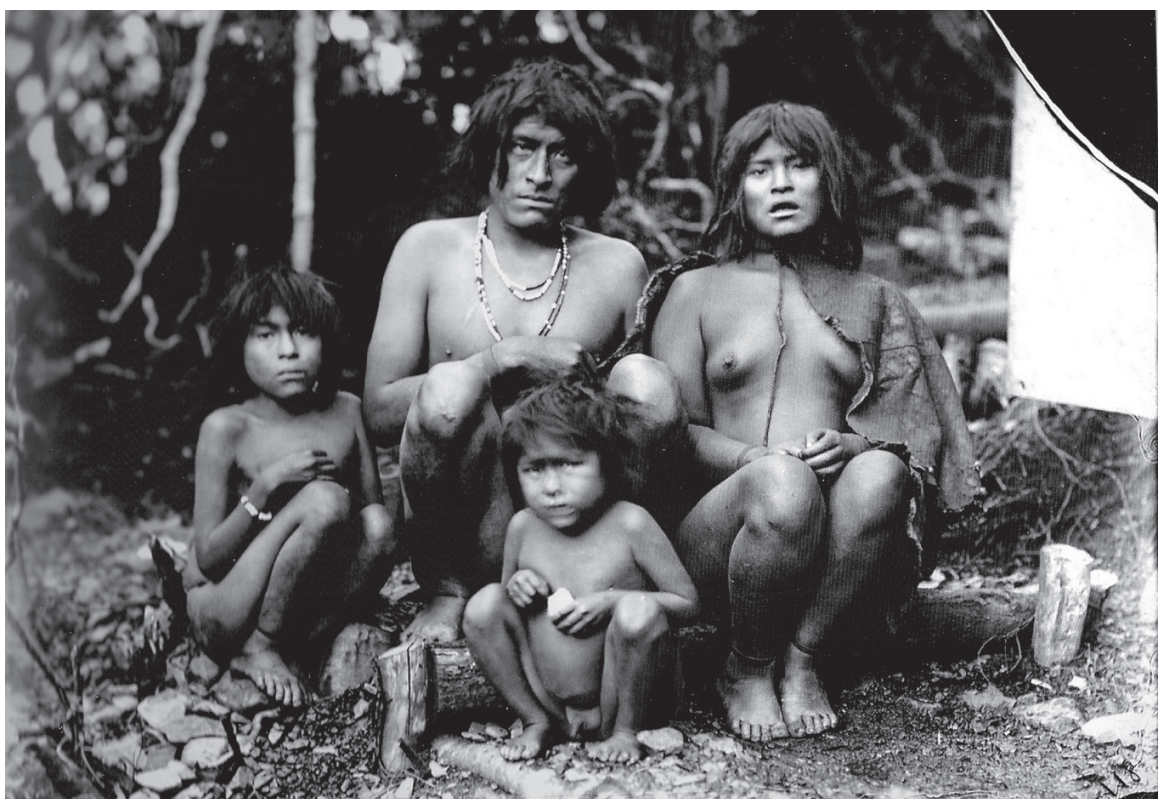

Fotografía de Jean Louis Doze y Edmond Payen, Misión Científica al Cabo de Hornos, 1882-1883.

\section{Tabla 2}

\section{Tipos de brazalete por género}

\begin{tabular}{|l|c|c|c|c|c|}
\hline \multirow{2}{*}{$\begin{array}{c}\text { Tipo de } \\
\text { brazalete/ } \\
\text { Género }\end{array}$} & Autóctonos & \multicolumn{3}{c|}{ Foráneos } & \multirow{2}{*}{ Total } \\
\cline { 2 - 5 } & cuero & $\begin{array}{c}\text { cuentas } \\
\text { blancas }\end{array}$ & $\begin{array}{c}\text { cuentas } \\
\text { oscuras }\end{array}$ & $\begin{array}{c}\text { cuentas blancas } \\
\text { y oscuras }\end{array}$ & \\
\hline Mujeres & 6 & 3 & 1 & 4 & 14 \\
\hline Varones & 3 & 3 & - & - & 6 \\
\hline Total & 9 & 6 & 1 & 4 & 20 \\
\hline
\end{tabular}

Elaboración: Autoras 
$\mathrm{Al}$ igual que en el caso de los collares, eran las mujeres quienes más usaban brazaletes (70\% de 20 brazaletes), aunque también se los ve en algunos varones (30\%). De los cuatro tipos de brazalete identificados en las fotos, las mujeres usaban los cuatro y los hombres solo dos, mostrando que las mujeres vestían mayor cantidad y variedad de brazaletes. Este predominio se registra tanto en los brazaletes autóctonos (66\% de 9) como en los foráneos (72\% de 11). Ahora bien, los brazaletes foráneos presentan una situación más compleja: los brazaletes de cuentas blancas eran usados por mujeres y varones en la misma proporción (50\% cada género), mientras que los brazaletes de cuentas oscuras y los que mezclaban cuentas blancas y oscuras eran usados solamente por mujeres.

Así, las fotografías documentan una interesante regulación de género: tanto los brazaletes autóctonos de tiento como los brazaletes foráneos de cuentas eran más usados por las mujeres que por los varones. Este predominio del uso femenino de brazaletes puede vincularse con las observaciones realizadas por algunos viajeros respecto de que eran las mujeres adultas y las niñas las que usaban los brazaletes (Hyades y Deniker, 2007 [1891]; Gusinde, 1986 [1937]).

Las tobilleras fueron observadas también por muchos de los viajeros que entraron en contacto con los Yámana/Yagán (Fitz Roy, 1839; Martial, 2007 [1888]; Hyades y Deniker, 2007 [1891]; Gusinde, 1986 [1937]). Las tobilleras autóctonas tenían unos $2 \mathrm{~cm}$ de ancho y podían estar confeccionadas en cuero de lobo marino o de guanaco, y no hay evidencia del uso de tobilleras foráneas (Orquera y Piana, 2015). A diferencia de los collares y los brazaletes, las tobilleras fotografiadas presentan muy baja variabilidad, ya que solo aparecen las autóctonas de cuero (Figura 6).

Estas tobilleras fueron usadas casi exclusivamente por mujeres (96\%) (Tabla 3); de hecho, un único varón Yámana/Yagán fue fotografiado usando una tobillera de cuero. De esta manera, las tobilleras presentan una regulación de género muy marcada, ya que parecen haber sido usadas casi exclusivamente por mujeres ${ }^{10}$.

10 Las tobilleras, aunque usadas casi exclusivamente por mujeres, no parecen estar asociadas a ningún rito de pasaje exclusivamente femenino, como la primera menstruación. Esta afirmación se basa en que: a) las tobilleras eran usadas indistintamente por adultas, jóvenes y niñas -aunque las últimas no habrían pasado por ese rito de pasaje-; b) ninguno de los viajeros y etnógrafos que registró datos sobre los Yámana/Yagán mencionó la asociación de las tobilleras con ese rito de pasaje y c) la única ornamentación asociada a ese ritual de pasaje femenino parece haber sido la pintura corporal (Fiore, 2002). 
Figura 6

Yámanas/Yaganes vistiendo collares de cuentas y la mujer vistiendo dos tobilleras de cuero

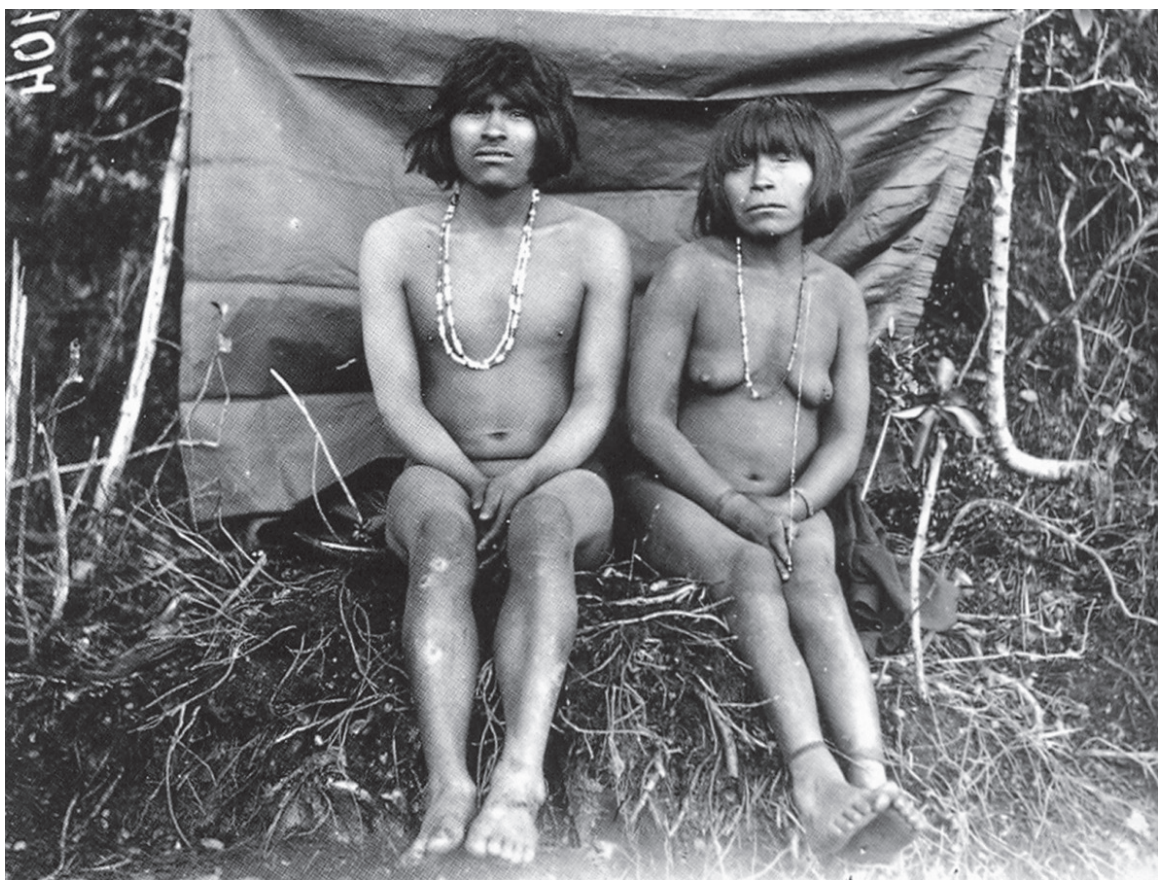

Fotografía de Jean Louis Doze y Edmond Payen, Misión Científica al Cabo de Hornos, 1882-1883.

Tabla 3

Tipo de tobilleras por género

\begin{tabular}{|l|c|}
\hline \multirow{2}{*}{ Tipo de tobilleras / Género } & Autóctonas \\
\cline { 2 - 2 } & cuero \\
\hline Mujeres & 26 \\
\hline Varones & 1 \\
\hline Total & 27 \\
\hline
\end{tabular}

Elaboración: Autoras 


\section{Discusión y reflexiones finales: una arqueología del registro visual fueguino}

A la hora de discutir estos resultados consideramos crucial tener en cuenta la demografía fotográfica que planteamos al comienzo del análisis, ya que muestra que en el corpus de fotografías etnográficas de Yámanas/ Yaganes existió una representación equilibrada de varones y mujeres, con un leve predominio de varones (52\%). De esta manera, el predominio de un tipo de adorno, femenino o masculino, no puede ser adjudicado a la mayor representación de un género, sino al predominio del uso de esos adornos. Esto por supuesto no implica que dicho registro sea una muestra objetiva de la realidad pasada (Barthes, 2004), pero permite, mediante una mirada arqueológica del registro fotográfico, "excavar" pautas y tendencias de uso de la cultura material ornamental, como parte de las formas de construcción y regulación de los géneros dentro de la sociedad Yámana/Yagan.

$\mathrm{Al}$ analizar los collares, brazaletes y tobilleras de acuerdo al género de quien los portaba, encontramos que la amplia mayoría de estos adornos corporales eran usados por mujeres ( $71 \%$ de 171 adornos). De estos tres tipos de adornos, los collares eran los más compartidos por mujeres (66\%) y varones (34\% de 124 collares); mientras los brazaletes eran usados en mayor proporción por mujeres (70\%) que por varones (30\% de 20 brazaletes); y las tobilleras lo eran casi exclusivamente por mujeres (96\% de 27 tobilleras) (Tabla 4).

Tabla 4

Tipo de adornos corporales por género

\begin{tabular}{|l|c|c|c|c|}
\hline \multicolumn{1}{|c|}{ Adornos/ Género } & Collares & Brazaletes & Tobilleras & Total \\
\hline Mujeres & 82 & 14 & 26 & 122 \\
\hline Varones & 42 & 6 & 1 & 49 \\
\hline Total & 124 & 20 & 27 & 171 \\
\hline
\end{tabular}

Elaboración: Autoras

Entendemos que el género implica una construcción social e histórica, fruto del efecto de la asignación de roles culturales a cada individuo según su corporalidad (incluyendo y excediendo a su sexo) y de la forma en que éste los asume, reproduce y/o desafía, mediante una creación y/o repe- 
tición ritualizada de gestos corporales y actos de habla (Conkey y Spector, 1984; Claassen, 1992; Butler, 2004). De esta manera, el género es siempre performativo, en tanto exige una actuación reiterada y estilizada de gestos, movimientos y estilos corporales socialmente determinados como parte de distintos géneros -que en el caso que nos ocupa hemos definido operativa y dicotómicamente como femenino o masculino, aunque reconocemos la existencia de variaciones internas- (Fiore, 2007). Esos actos, gestos y movimientos corporales son performativos, ya que refieren a una identidad de género visible mediante prácticas concretas -el vestir, el ornamentarse, el hablar-, inteligibles dentro de un campo cultural (Sørensen, 2000; Butler, 2004). Así, las prácticas asociadas a cada género son autopercibidas y percibidas por los otros como parte de ese género.

A partir de esta concepción de género, consideramos a los adornos corporales como parte de esas performances de género, en tanto el uso de adornos llevan al desarrollo de estilos corporales que habilitan tanto la autopercepción como la percepción por otros. Los adornos corporales son así experimentados en su uso corporal (se atan, se cuelgan, se enroscan e incluso perforan partes del cuerpo), pero también son exhibidos para un otro, que los decodifica como pertenecientes (o no) a un género, según los hábitos y regulaciones de género de su sociedad. Así, entendemos que en el caso Yámana/Yagán, el uso preferentemente femenino de collares, brazaletes y tobilleras podría referir a una "construcción visual diferencial del género femenino yámana” (Fiore y Varela, 2009, p. 219). Los collares eran los adornos más frecuentemente usados en la sociedad, y los que más se compartían entre mujeres y varones (aunque predominaban entre las primeras). Sin embargo, algunos tipos de collares parecen haber sido de uso exclusivo de cada género: los collares de hueso y de caracoles aparecen usados solo por mujeres y los collares de cuero solo por varones. De esta manera, es posible considerar que los collares autóctonos señalarían diacríticamente a su portador como perteneciente al género femenino o masculino; mientras los alóctonos habrían sido de uso indistinto respecto del género. En los Yámana/Yagán los brazaletes y las tobilleras aparecen visualmente más asociados al género femenino. En tal sentido, las inferencias efectuadas a partir de esta arqueología visual del registro fotográfico de este pueblo originario fueguino sugieren que mientras los collares foráneos implicaban regulaciones de género un poco más laxas, los collares autóctonos y las tobilleras implica- 
ban regulaciones de género bastante más estrictas, siendo los brazaletes un caso comparativamente intermedio.

Estas diferencias podrían surgir del hecho de que los collares foráneos habrían constituido una "novedad" atractiva para ambos géneros, que no habría estado impregnada de valores socioculturales que afectaran la regulación de su uso respecto del género del portador. Contrariamente, los ornamentos autóctonos habrían estado impregnados de valores socioculturales tradicionales más difíciles de cambiar, pese a que se registran algunas variaciones en su uso, tal como hemos documentado en las respectivas tablas de datos.

Es posible pensar que la presencia del fotógrafo podría haber influido en la construcción del registro fotográfico de estos ornamentos, especialmente porque las mujeres eran las más fotografiadas usando estos adornos. Los fotógrafos podrían haber favorecido tomas en las cuales las mujeres portaran collares, brazaletes y tobilleras, siguiendo sus propias normas occidentales, en las cuales se asocia lo femenino con la ornamentación y la "coquetería". La existencia de tomas en las cuales las mujeres aparecen como "cuerpos dóciles" (Masotta, 2003) y modelos eróticos (Carreño, 2002) es consistente con esta posibilidad. Sin embargo, también cabe señalar que, aunque más mujeres fotografiadas usaran ornamentos, no se ha registrado una homogeneidad de géneros en los tipos de ornamentos usados, ni tampoco patrones enteramente azarosos, opciones de lo que podria haber ocurrido si las fotografías hubieran sido producidas de acuerdo al imaginario de los fotógrafos. Es aquí donde consideramos que entra a operar la agencia de los propios sujetos fotografiados (sensu Giddens, 1995; Fiore, 2007; Fiore y Varela, 2009), ya que las tendencias halladas en el uso de tipos de ornamentos habrían sido generadas por las propias prácticas y hábitos de las personas fotografiadas, interpretables como señales de las performances de género de los Yámana/Yagán.

De esta manera, consideramos que la antropología visual puede enriquecerse mediante una mirada arqueológica, al recuperar el valor etnográfico de las fotografías y tratarlas como artefactos que aportan información sobre pautas de comportamiento de estas poblaciones indígenas en el pasado reciente. El análisis sistemático y profundo de estos artefactos visuales permite aportar nuevos datos acerca de la forma en que las sociedades indígenas construían los roles y regulaciones de género, mostrando que existieron múltiples formas de pensar y actuar lo femenino y lo masculino. 


\section{Agradecimientos}

Los resultados aquí presentados forman parte de las investigaciones llevadas a cabo por las autoras en el marco del CONICET y la AIA. Agradecemos especialmente a los museos y archivos y al ARC-FOT-AIA, donde hemos podido recopilar la muestra fotográfica aquí analizada. Expresamos también nuestra gratitud a Luis Orquera, director de la AIA y experto en arqueología de la región habitada por los Yámana/Yagán, por su constante apoyo a nuestras investigaciones y sus atinados comentarios al manuscrito.

\section{Bibliografía}

Alvarado, M. (2007). Vestidura, investidura y despojo del nativo fueguino. En M. Alvarado, C. Odone, F. Maturana \& D. Fiore (Eds.), Fueguinos. Fotografías siglos XIX y XX. Imágenes e imaginarios del fin del mundo (pp. 61-73). Santiago de Chile: Pehuén.

Alvarado, M. y P. Mason (2005). Fueguia Fashion. Revista Chilena de Antropología Visual 6, 2-18.

Báez, C., y Mason, P. (2006). Zoológicos humanos. Fotografías de fueguinos y mapuche en el Jardin d'Acclimatation de París, siglo XIX. Santiago de Chile: Pehuén.

Báez, C. (2005). Uso y abuso la construcción del indígena fueguino en los textos escolares a través de la imagen fotográfica. Revista Chilena de Antropología Visual 6, 19-33.

Barthes, R. (2004). La cámara lúcida. Buenos Aires: Paidós.

Batchen, G. (2004). Arder en deseos. La concepción de la fotografía, Barcelona: Editorial Gili.

Bazin, A. (1960). The Ontology of the Photographic Image. Film Quarterly, 13(4), 4-9.

Benjamin, W. (2015). Estética de la imagen. Buenos Aires: La Marca editora.

Bourdieu, P. (1979). La fotografía: un arte intermedio. México: Nueva Imagen.

Bridges, L. (2005 [1948]). El último confín de la tierra. Buenos Aires: Sudamericana.

Butler, J. (2004). Regulaciones de género. Londres: Routledge, Taylor \& Francis Group.

Butto, A. (2016). MS Huellas visuales, huellas materiales. Sitios y artefactos de indígenas patagónicos y fueguinos registrados en las fotografías tomadas durante la conformación y expansión del estado-nación argentino 
(1860-1940) y sus implicancias para el registro arqueológico. Tesis Doctoral. Universidad de Buenos Aires: Facultad de Filosofía y Letras.

Carreño, G. (2002). Fotografías de cuerpos indígenas y la mirada erótica: reflexiones preliminares sobre algunos casos del confín austral. Revista Chilena de Antropología Visual 2, 133-153.

Claassen, C (1992). Exploring Gender through Archaeology: Selected Papers from the 1991 Boone Conference. Madison: Monographs in World Archaeology 11 , Prehistory Press.

Conkey, M y Gero, J (1991). Engendering Archaeology: Women and Prehistory. Oxford: Blackwell.

Conkey, M and Spector, J (1984). Archaeology and the study of gender. En M. Schiffer (Ed.), Advances in Archaeological Method and Theory 7 (pp. 1-38). New York: Academic Press.

Collier, J. (1995). Photography and visual anthropology. Hockings, 235-254.

Costa, J. (1991). La fotografía, entre sumisión y subversión. México: Editorial Trillas.

Dubois, P. (2008 [1990]). El acto fotográfico y otros ensayos. Buenos Aires: La Marca Editora.

Edwards, E. (1992). Anthropology and Photography 1860-1920. Londres: Yale University Press.

Fiore, D. (2002). Body Painting in Tierra del Fuego. The power of images in the uttermost part of the world. Tesis Doctoral. London: University of London.

Fiore, D. (2005). Fotografía y pintura corporal en Tierra del Fuego: un encuentro de subjetividades. Revista Chilena de Antropología Visual 6, 55-73.

Fiore, D. (2007). Painted genders. The construction of gender through the display of body painting by the Selk'nam and the Yámana from Tierra del Fuego (Southern South America). En Women and Archaeology (pp. 373-404). California: Left Coast Press.

Fiore, D. y M. L. Varela (2009). Memorias de papel. Una arqueología visual de las fotografías de pueblos originarios fueguinos. Buenos Aires: Editorial Dunken.

Fitz-Roy, R. (1839). Narrative of the surveying voyage of his majesty's ships Adventure and Beagle between the years 1826 and 1836. Londres: Henry Colburn.

Flusser, W. (1990). Hacia una filosofía de la fotografía. México: Editorial Trillas.

Freund, G. 2015 [1974]. La fotografía como documento social. Barcelona: Editorial Gustavo Gili.

Giddens, A. (1995). La constitución de la sociedad: Bases para la teoría de la estructuración. Buenos Aires: Amorrortu. 
Grimshaw, A. (2001). The Etnographer's Eye. Ways of seeing in anthropology. Londres: Cambridge University Press.

Gusinde, M. (1986 [1937]). Los indios de Tierra del Fuego. Los Yamanas. I-II-III. Buenos Aires: Consejo Nacional de Investigaciones Científicas.

Hyades, P. y J. Deniker (2007 [1891]). Etnografía de los indios yaghan en la Misión científica del Cabo de Hornos 1882-1883. Punta Arenas: Ediciones Universidad de Magallanes.

Kossoy, B. (2001). Fotografía e historia. Buenos Aires: La Marca Editora.

Martial, L. F. (2007 [1888]). Etnografía de los indios yaghan en la Misión científica del Cabo de Hornos 1882-1883. Punta Arenas: Ediciones Universidad de Magallanes.

Masotta, C. (2003). Cuerpos dóciles y miradas encontradas. Miniaturización de los cuerpos e indicios de la resistencia en postales de indios argentinas (1900-1940). Revista Chilena de Antropología Visual 3, 1-16.

Naranjo, J. (2006). Fotografía, antropología y colonialismo. Barcelona: Editorial Gustavo Gili.

Orquera, L. y E. Piana (1999). Arqueología de la Región del Canal Beagle (Tierra del Fuego, República Argentina). Buenos Aires: Sociedad Argentina de Antropología.

Orquera, L. y E. Piana (2015 [1999]). La vida social y material de los Yámana. Ushuaia: Monte Olivia.

Peirce, C. (1995). Philosophical writings of Peirce. New York: Dover Publications.

Penhos, M. (2005). Frente y perfil. Fotografía y prácticas antropológicas y criminológicas en Argentina a fines del siglo XIX y principios del XX. En Arte y antropología en la Argentina. Buenos Aires: Fundación Telefónica / Fundación Espigas / FIAAR.

Poole, D. (2000). Visión, raza y modernidad. Una introducción al mundo andino de imágenes. Lima: Casa de Estudios del Socialismo.

Ruby, J. (1996). Visual Anthopology, En D. Levinson y M. Embers (Eds.), Encyclopedia of Cultural Anthropology 4 (pp. 1341-1351). New York: Henry Holt and Company.

Saletta, M. J. (2011). Fotografías de indígenas en manuales escolares argentinos: representaciones visuales y connotaciones textuales. Intersecciones en Antropología, 13, 181-195.

Scherer, J. C. (1995). Ethnographic photography en anthropological research. Hockings, 201-216. 
Sørensen, ML (2000). Gender Archaeology. Cambridge: Polity Press.

Tagg, J. (2005). El peso de la representación. Barcelona: Editorial Gustavo Gili.

Fecha de recepción: 22/05/2017; fecha de aceptación: 28/07/2017;

fecha de publicación: 01/09/2017 